\title{
E-COMMERCE: DESAFIOS NA CAPTAÇÃO DE CLIENTES EM UMA LOJA D O SEGMENTO DE ESSÊNCIAS
}

https://dx.doi.org/10.48097/2674-8673.2021n5p06

Erivaldo Severino de Santana ${ }^{1}$

Suzany Pereira ${ }^{2}$

Arandi Maciel Campelo ${ }^{3}$

\section{RESUMO}

Este artigo tem como objetivo mostrar os desafios da captação e fidelização de clientes em uma empresa do ramo de essências. Este artigo aborda os tipos de e-commerce e suas modalidades, como também relata métodos e maneiras práticas de captar e fidelizar clientes de maneira que eles não só se satisfaçam, mas fiquem encantados. Este trabalho inclui pesquisa sobre redes sociais como ferramenta de e-commerce. O campo investigativo foi a loja La Bella Essenza, sendo aplicado um questionário semiaberto, em 2020. O referencial teórico teve como principal balizador Fagundes (2009). Este trabalho demonstra como as redes sociais se tornaram uma arma indispensável nos dias de hoje para quem vende pela internet.

Palavras-chave: Redes Sociais. Captação e fidelização de clientes. E-commerce.

Data de submissão: $25 / 02 / 2021$

Data de aprovação: 29/03/2021

\begin{abstract}
This article aims to show the challenges of attracting and retaining customers in a company in the field of essences. This article discusses the types of e-commerce and its modalities, as well as reports methods and practical ways to attract and retain customers so that they are not only satisfied, but also delighted. This work includes research on social networks as an ecommerce tool. The investigative field was the La Bella Essenza store, using a semi-open questionnaire, in 2020. The theoretical framework was based on Fagundes (2009). This work

1 Estudante do curso de Administração da Faculdade Metropolitana da Grande Recife.

E-mail: juniofb9@gmail.com

2 Estudante do curso de Administração da Faculdade Metropolitana da Grande Recife.

E-mail: suzannyfenix30@gmail.com

3 Orientador: Doutor em Educação - Universidade Federal de Pernambuco; Administrador - Universidade de Pernambuco - FCAP/UPE; Mestre em Planificación y Gestion Organizacional - Universidad Autonoma de Madrid / Espanha; Mestre em Dirección y Organización de Hospitales y Servicios de Salud - Universidad Politécnica de Valencia / Espanha; Especialista em Marketing - FCAP/UPE; Consultor em Sistemas Organizacionais, desde 1984; Professor e Diretor Acadêmico da Faculdade Metropolitana da Grande Recife. E-mail: arandi.campelo@globo.com
\end{abstract}


demonstrates how social networks have become an indispensable weapon nowadays for those who sell over the internet.

Keywords: Social Networks. Attracting and retaining customers. E-commerce.

\section{INTRODUÇÃO}

Nesse novo cenário em que vivemos empresas de vários segmentos viram oportunidades de expandirem seus negócios utilizando o e-commerce e suas várias modalidades. Com a expansão do comércio eletrônico muitas empresas precisaram desenvolver novas estratégias para conquistar novos clientes e fidelizar os já existentes. A satisfação dos usuários do e-commerce passou a ser fator determinante de sucesso.

A pesquisa de campo foi realizada na empresa La Bella Essenza, uma distribuidora localizada em Jaboatão dos Guararapes. O tema escolhido é de grande importância para demostrar a dependência que a internet traz ao empreendedor, por se tratar de uma poderosa aliada ao empreendimento no e-commerce e nas redes sociais, refletindo na captação e fidelização de clientes.

\section{REFERENCIAL TEÓRICO}

Este trabalho teve com principal balizador Fagundes (2009), embora tenham sido utilizados outros autores para o embasamento deste artigo, como Kotler (2017) e Gonçalves (2007).

\section{E-commerce}

O comércio eletrônico é definido como qualquer transação comercial que envolva os processos de negócios através de um ambiente eletrônico, por exemplo, a internet. O fundador da rede americana Sears, Richard Sears, começou seu negócio vendendo relógios através de telegramas para seus colegas na época em que era agente de estação de trem, no final do século 19, com uma margem muito pequena de lucro.

O comércio eletrônico, como conhecemos hoje, iniciou no final da década de 1960. Desde 1993, novas tecnologias permitem às empresas realizar funções e-business ${ }^{4}$ com maior eficiência, rapidez e menores custos do que jamais foi possível.

4 E-business, acrônimo do inglês Electronic Business (negócio eletrônico), é o termo que se utiliza para identificar os negócios efetuados por meios eletrônicos, geralmente na internet. 
Segundo Fagundes (2009):

O comércio eletrônico através da internet é o ramo de atividade econômica que mais cresce no mundo. As jovens empresas que ingressam no comércio on-line têm atraído o maior número de investidores do mercado de ações, aumentando o valor de mercado de forma alucinante. (FAGUNDES, 2009, p. 01).

E-commerce ${ }^{5}$ é todo o comércio realizado através de meios eletrônicos. É a compra e venda de bens e serviços ou a transmissão de fundos ou dados, através de uma rede eletrônica, principalmente a internet.

Para se entender a principal diferença entre e-business e e-commerce é que o segundo é como um subproduto do primeiro. E-business aborda todo o processo de negociação que uma empresa faz pela internet e e-commerce as transações comerciais de bens e serviços on-line. Então, todo e-commerce é um exemplo de e-business.

O e-commerce surgiu em 1970 com a EDI e EFT ${ }^{6}$ fazendo transferências de valores entre pessoas e empresas, mas foi com a internet que ganhou força e ficou disponível para todas as pessoas.

Os benefícios do comércio eletrônico incluem disponibilidade 24 horas, velocidade de acesso, ampla disponibilidade de bens e serviços para o consumidor, fácil acessibilidade e alcance internacional. (GONÇALVES, 2007).

Enquanto os compradores em uma loja física podem ser mais lentos pelas multidões, os sites de comércio eletrônico são executados rapidamente, o que é determinado por considerações de computação e largura de banda no dispositivo do consumidor e no site de comércio eletrônico.

A esse respeito, conforme cita Campano (2010):

Iniciar um negócio on-line é bem simples, se comparado a um negócio tradicional. Não exige muito dinheiro ou tempo para iniciar e as formas de se fazer dinheiro com um negócio on-line são muitas: vendendo produtos reais ou digitais, criando websites ou logotipos para empresas, criando um blog, criando comunidades interessadas em um certo tema etc. De fato, muitas pessoas fizeram e estão fazendo muito dinheiro com seu negócio online. (CAMPANO, 2010, p. 01).

5 E-commerce (ou "comércio eletrônico" em português) é uma modalidade de comércio em que os negócios e transações financeiras são realizadas via dispositivos e plataformas eletrônicas, como computadores, tablets e smartphones.

6 Emotional Freedom Techniques, ou Técnica de Libertação Emocional e Electronic Data Interchange, ou, em português, Intercâmbio Eletrônico de Dados. 
Há algum tempo atrás não havia muitos outros meios de realizar compras se não fosse de forma física, ou seja, sair do conforto de casa e ir até a loja comprar o produto. Aqui no Brasil, por exemplo, o comércio eletrônico tem menos de duas décadas de existência.

A evolução desse tipo de comércio esteve sempre muito interligada com o desenvolvimento da internet. Assim, com a popularização da internet (por volta da segunda metade da década de 90), o comércio eletrônico começou a operar semelhantemente como é hoje. Nessa época, então, o comércio eletrônico deixou de ser tendência e se tornou uma realidade sólida para os que gostam de facilidade e praticidade na hora de comprar alguma mercadoria ou produto.

É comum que quem ainda não tenha boa prática com a internet esteja cercado de dúvidas sobre como funcionam os tipos de comércio eletrônico. Quando pensamos em ecommerce logo vem em mente um site que vende produtos para um consumidor final. Porém, há muitas empresas que vendem para outras empresas e usam a internet como estratégia comercial. (CARDOSO, 2012).

Hoje, a TV digital, por exemplo, conta com muitos recursos que permitem uma maior interatividade do telespectador e que novos campos sejam explorados. O t-commerce oferece uma nova forma de receitas financeiras para emissoras, serviços de streaming, marcas etc.

\section{Redes sociais como ferramentas do e-commerce}

Quando se fala em estratégias de marketing digital para e-commerce, uma das mais lembradas é o marketing para redes sociais que hoje faz parte de nosso cotidiano. É por meio delas que as pessoas se comunicam, se atualizam, fazem trocas, vendem, entre outras diversas atividades. Hoje grande parte das lojas virtuais já tem sua página no Facebook, Instagram, YouTube ou em outras mídias sociais. E mesmo aquelas que não têm perfis nessas plataformas também estão presentes nesse contexto. Com as redes sociais, eles esperam muito mais de uma empresa do que apenas comprar e vender. Por esse motivo é preciso ter diálogo, conteúdo, confiança e até mesmo descontração. São detalhes que humanizam mais a relação entre marcas e consumidores, criando diferenciais para que o público não seja convencido apenas por preço ou conveniência. (KIYOSAKI, 2013).

O uso das redes sociais para o e-commerce reforça a importância dessas ferramentas na atração de clientes. A loja virtual pode conhecer melhor o seu público-alvo, suas preferências e necessidades para, então, se aproximar do cliente que tem interesse nos produtos ou 
serviços. Outro benefício importante, além de atrair clientes, é o poder de segmentação das redes, especialmente nas plataformas de anúncios. Manter interação exclusivamente comercial é algo que raramente seduz e fideliza os clientes. Com as redes sociais, eles esperam bem mais da empresa do que apenas comprar.

Esses detalhes tornam a relação com os consumidores mais estreita e humanizada, criando um diferencial para o público. Um perfil na web que proporciona discussões interessantes e que compartilha conteúdos relevantes para os seguidores, ajudando a melhorar a credibilidade da empresa.

Esse tipo de comportamento aumenta também o engajamento e a educação do cliente. Certamente você já viu várias promoções de produtos nas redes sociais de lojas virtuais que querem chamar a atenção do público. Essa técnica, quando bem aplicada, pode gerar resultados positivos nas vendas, além de tornar a marca ainda mais conhecida no mercado. Sem dúvida, uma característica comum dessas redes é o custo reduzido, quando comparado aos meios tradicionais de marketing, como propaganda em mídias de massa como a televisão. Além disso, o investimento pode ser flexível, já que o e-commerce pode escolher em qual ação ou campanha quer investir mais.

Existem tantas opções de mídias sociais atualmente que pode ser um pouco difícil escolher em qual estar presente.

Facebook - Essa é a maior rede social do mundo e, por isso, muito importante para o comércio eletrônico. Tem aplicação bem ampla, com postagens de conteúdos em textos, imagens e vídeos, permitindo uma conexão próxima com o público. Além disso, ela oferece a opção de anúncios publicitários pagos, veiculados dentro da plataforma e de outras redes do mesmo grupo, como o Instagram.

Instagram - O foco do Instagram está voltado para o aspecto visual. A rede é usada para compartilhamento de imagens e vídeos, com grande potencial de engajamento do público. É a mídia ideal para apresentar novos produtos aos consumidores.

YouTube - Plataforma mais popular de veiculação e compartilhamento de vídeos, o YouTube consegue obter grande participação do público por meio dos seus conteúdos, sobretudo devido a forte presença de influenciadores digitais. Nos últimos anos a rede ganhou muito destaque, pois os conteúdos em vídeos viraram tendência.

LinkedIn - É uma rede social empresarial, voltada para um público que deseja estabelecer relações profissionais. Em geral, a plataforma atrai usuários mais formais, mas 
deve seguir a cultura da empresa e apresentar conteúdos bem segmentados. Tudo isso por meio de conteúdos como textos, infográficos e vídeos que entregam informações relevantes e constroem um relacionamento com os consumidores.

Estar presente em todas elas pode ser um pouco complicado e gerar um trabalho desnecessário e improdutivo. Portanto, deve-se escolher e ser ativo nas redes mais adequadas a cada loja e público. O perfil traçado do cliente ajudará a escolher a plataforma ideal. Por fim, fica evidente a importância de utilizar as redes sociais para e-commerce, já que elas são os principais canais de interação com os consumidores no mundo digital e uma das melhores formas de atrair novos clientes.

\section{Captação e fidelização de clientes}

Conquistar a clientela é uma das tarefas mais importantes para a sobrevivência de qualquer negócio. Uma boa alternativa é criar propostas satisfatórias em busca de reter clientes para manter sempre a empresa em crescimento constante, criando inúmeras formas de satisfazê-los com o intuito de captar e cativar cada vez mais. As empresas têm que adotar métodos de captação e fidelização através de pesquisas relacionadas ao nível de satisfação de produtos e serviços; ao atendimento; sobre como está a visualização dos produtos da empresa em sites, revistas, outdoors etc.; como está sendo a experiência de utilizar os produtos ou serviços prestados no dia a dia; e buscar saber dos clientes sua opinião sobre novos produtos.

Para Kotler (2017):

O valor entregue ao cliente é a diferença entre o valor total para o cliente e o custo total para o cliente. $\mathrm{O}$ valor total para o cliente é o conjunto de benefícios que os clientes esperam de um determinado produto ou serviço. O custo total para o cliente é o conjunto de custos em que os clientes consumidores esperam incorrer para avaliar, obter, utilizar e descartar um produto ou serviço. (KOTLER, 2017, p. 01).

Não basta apenas criar uma proposta de valor, ela tem que ser acompanhada e entregue. Essa estratégia envolve toda experiência que os clientes obterão ao interagir com os serviços ou produtos.

$\mathrm{O}$ valor prometido pela organização deve corresponder às expectativas dos clientes, incluindo comunicação, canais que foram utilizados para que as informações cheguem até eles e todo caminho percorrido pelo cliente até obter o que procura, conforme o que lhe foi prometido. 
Fidelizar clientes é uma tarefa que requer atenção da empresa. É nesse ponto que muitas delas não se atentam, pois exige esforço, tempo, dedicação, recursos pessoais e financeiros para as campanhas de fidelização dar certo.

Para Kotler (2017) existem gradações nessa fidelidade, dividida em quatro categorias que ele chama de status.

- Clientes fiéis convictos: são aqueles consumidores que têm o hábito de comprar sempre da mesma marca.

- Clientes fiéis divididos: um tipo de consumidor que é fiel a mais de uma marca, podendo ser 2 ou 3.

- Clientes fiéis inconstantes: estão mudando de marca a todo o momento.

- Clientes infiéis: não têm preferência ou fidelidade por marca alguma.

(KOTLER, 2017, p. 01)

No questionamento descrito por Kotler (2017), considerando essa classificação, ele recomenda que as organizações façam um levantamento analítico de seus clientes fiéis convictos para estudarem seus pontos fortes e analisar o comportamento dos clientes fiéis divididos, criando meios para torná-los convictos da marca. Por último, analisar os clientes que estão mudando de marca o tempo todo e aqueles que não têm fidelidade por marca nenhuma, que é o caso dos clientes fiéis inconstantes e os infiéis, buscando entender por que agem de tal forma.

Kotler (2017) cita que para o negócio dar certo já não basta simplesmente satisfazer o cliente. É preciso encantá-lo. A empresa tem que ter por base essa ideologia, além de técnicas para captar e fidelizar sua clientela e assim se sobressair perante a concorrência.

A noção de fidelizar clientes está centrada na ideia de fazer com que eles se tornem clientes engajados, capazes de interagir com a marca nas redes sociais, interessados em novos produtos e campanhas e, claro, dispostos a comprar na sua loja por várias vezes.

Cardoso (2012) afirma que conquistar a fidelidade do cliente é, cada vez mais, o desafio das empresas, preocupadas não apenas com a competitividade, mas com a própria sobrevivência no mercado. Alcançar esse objetivo requer uma série de cuidados.

Em princípio, convém considerar a fidelidade como um tipo de comportamento complexo. Seja no campo das relações afetivas ou comerciais, fidelidade significa, em síntese, a confirmação de uma escolha, opção exclusiva por algo ou alguém e permanência dessa opção em um determinado tempo. 


\section{METODOLOGIA}

Vale destacar que este artigo tem como objetivo geral analisar as técnicas usadas pela loja La Bella Essenza na qualidade do atendimento, através das redes sociais como ferramenta do e-commerce, atuando na captação e fidelização de clientes.

O universo do campo pesquisado é composto por 4 gestores, cujos critérios para esta definição estão baseados nos cargos de liderança do setor administrativo. Destes, apenas 1 foi entrevistado.

A pesquisa que orientou este artigo foi de natureza bibliográfica, de campo e aplicada.

\section{DESENVOLVIMENTO DA PESQUISA DE CAMPO}

O campo investigativo deste artigo foi a loja La Bella Essenza, uma empresa do ramo de essências, localizada na cidade de Jaboatão dos Guararapes, Pernambuco.

$\mathrm{O}$ instrumento de campo utilizado na pesquisa foi um questionário semiaberto, constante no apêndice deste trabalho.

1. A empresa utiliza as redes sociais como marketing e comunicação para atrair clientes? Quais?

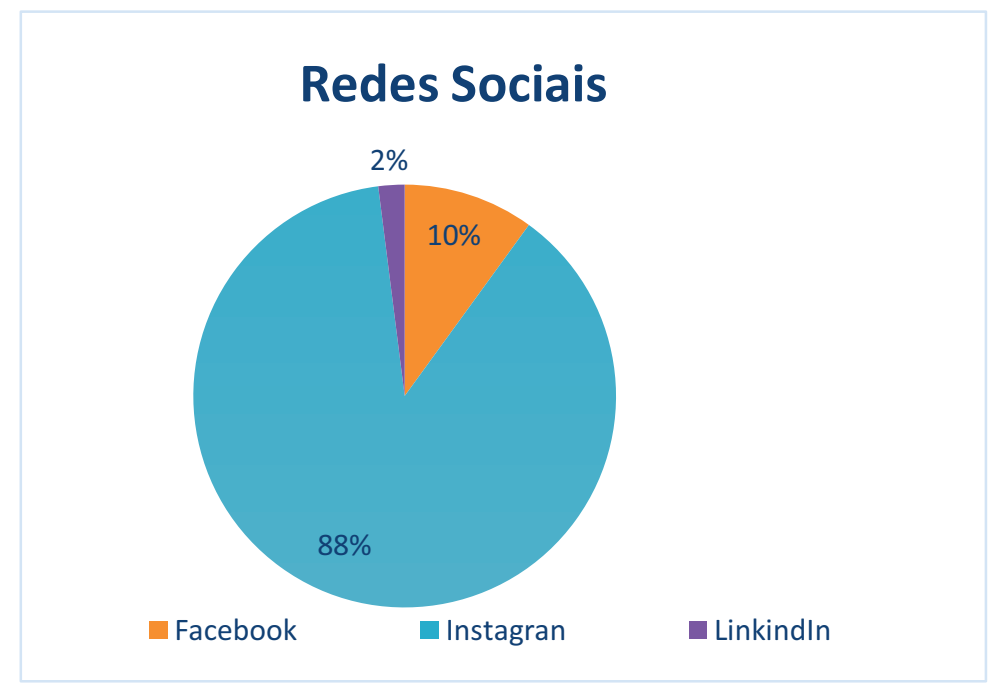

As respostas obtidas estão de acordo quando se fala sobre estratégia de marketing. Hoje, as redes sociais fazem parte do nosso cotidiano. Com o avanço na tecnologia e melhor acesso à internet existe uma facilidade muito grande na hora de conquistar o público-alvo através destas ferramentas. 
2. A empresa oferece promoções aos clientes? Essas promoções levam à fidelização?

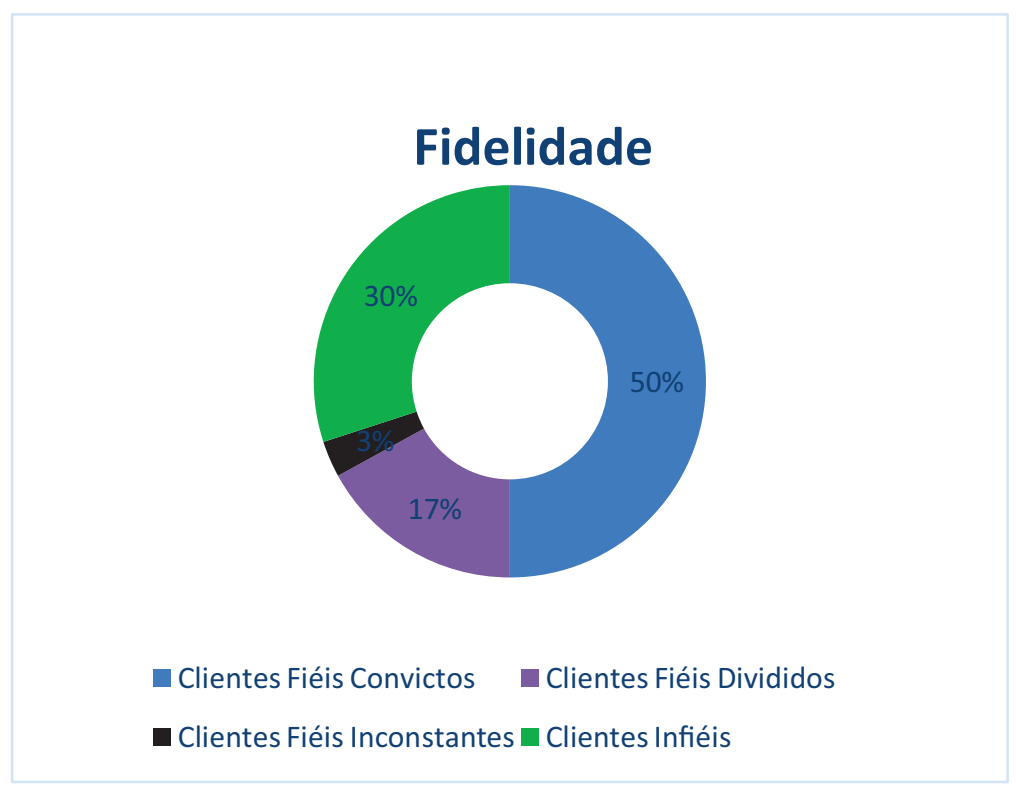

As repostas obtidas estão de acordo com as considerações de Kotler (2017) sobre os tipos de clientes.

3. A empresa tem política de fidelização de cliente?

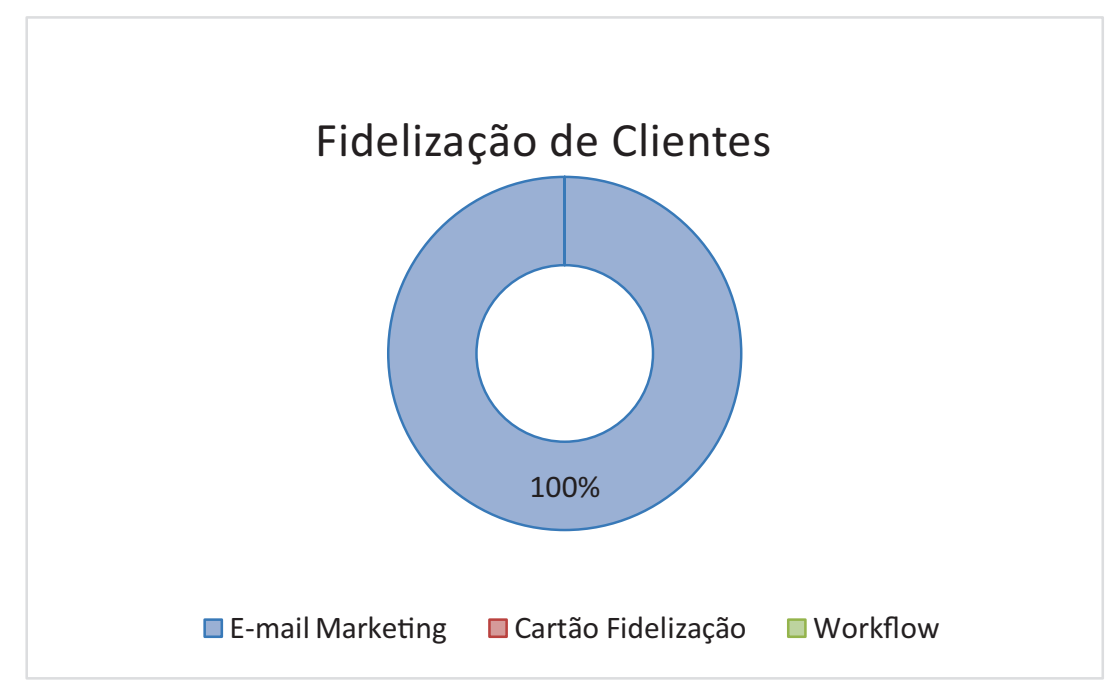

Apesar das várias maneiras de fidelização, a empresa utiliza apenas o e-mail marketing como forma de fidelizar seus clientes. 
4. Quais formas de pagamento a sua empresa utiliza?

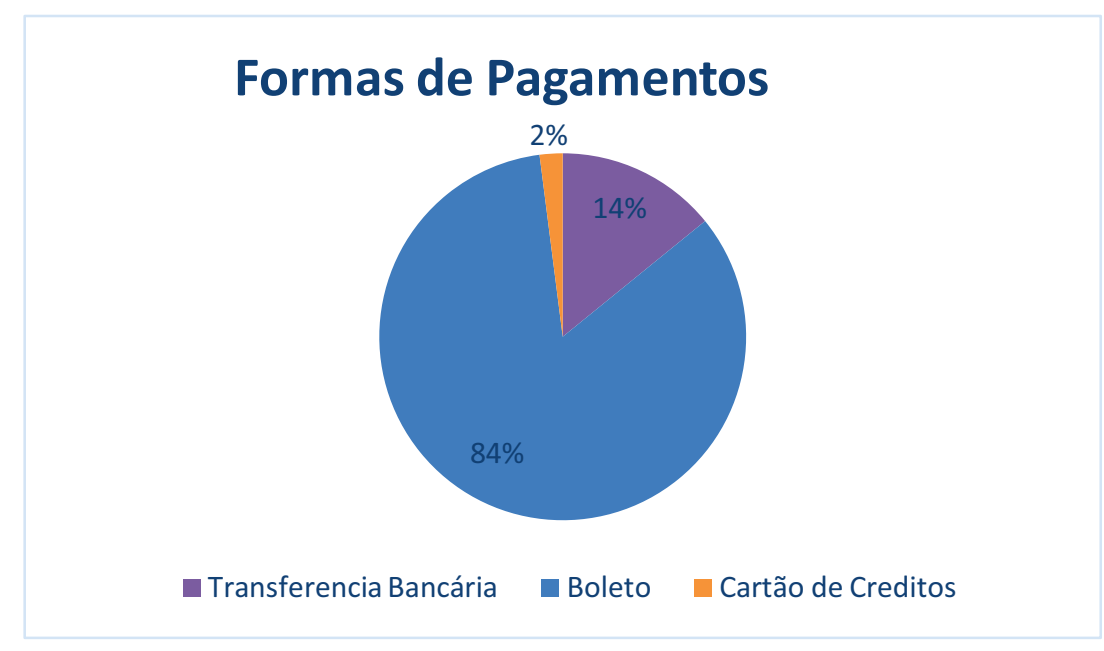

Sabemos que o boleto não é umas das formas mais seguras de pagamentos, porém, na maioria das vezes, é a única opção para poder atender ao cliente que não tem acesso ao cartão de crédito ou débito, ou até mesmo não ter limite no cartão. Apesar de poder existir inadimplências e prejuízos, o boleto é a forma de pagamento mais usada na empresa.

5. Quais tipos de logística a empresa aplica?

\section{Tipos de Logística}

- Produção

- Suprimentos

reverso

- Distribuição

Embora a empresa tenha respondido que trabalha apenas focada na logística de distribuição, observamos também atuação da logística de suprimentos, pelo fato deles também proporcionar não só a distribuição de material, mas conter no pacote qualidade, preço, e manter sempre estoque para seus clientes. 
6. Qual o número de visitantes mensais? E desses, quantos fidelizam o atendimento?

Ações nos seus anúncios

Os cliques no anúncio resultam em visitas ao seu site ou página de destino ou em chamadas para sua empresa. Quando alguém clica no seu anúncio, significa que ele está chamando a atenção e que as pessoas querem saber mais sobre sua empresa e o que você oferece.

Nós cobramos pelos cliques.

Origem dos cliques no seu anúncio

Para levar mais clientes até você pelo menor custo, exibimos seus anúncios no Google e nos sites parceiros. Saiba mais

\section{9}

Cliques
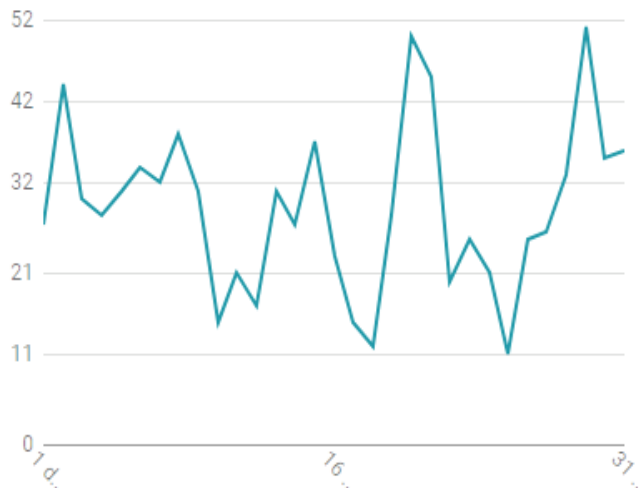

) 410

cliques no Google

410 Pesquisa Google

0 YouTube

$<$ TODAS AS CAMPANHAS

Essências Concentradas - La Bella Distr. Aromaty

ATIVA $\checkmark$

Anúncios exibidos há 2 horas

Último mês -

RS 316,54 Gastos do mês passado

@

36,9 mil

Impressões

A frequência com que seus

anúncios foram exibidos

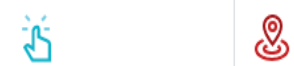

899

Cliques

Açoes de local

Açőes nos seus anúncios Açōes que mostram

intenção de visitar
हู)

42

Chamadas

Chamadas para sua

empresa
.0

\section{7}

Conversões

Açőes no seu site

relacionadas a anúncios

VER DETALHES DO DESEMPENHO

A média mensal de visitas (site e redes sociais) é de 899 acessos. 5\% é o retorno eficiente e convertido em vendas. Diante das pesquisas pode-se afirmar que esses clientes são aqueles que apenas buscam preços e não se importam com qualidade, bom atendimento ou assistência que a empresa pode oferecer. 


\section{CONSIDERAÇÕES FINAIS}

O foco deste artigo é demonstrar os desafios e a importância da ferramenta do ecommerce para a captação e fidelização de clientes no segmento de essências. É inegável que muitas empresas têm dificuldades ao usar essa ferramenta pelo fato de não buscar se aprimorar e mediante esse motivo sofrem frente às demais.

As redes sociais, hoje, estão se tornando um instrumento de proporções inimagináveis para auxiliar empresas que buscam esse tipo de segmento. É muito importante se esforçar ao máximo e trabalhar em cima de uma estratégia de captação de clientes bem definida para que depois eles se tornem leais à empresa, uma vez que as atenções da economia mundial estão voltadas para estabelecer conexão entre o mundo real e o virtual. Com o surgimento da internet e as mudanças no perfil de compra dos consumidores muitas empresas perceberam oportunidades de expandirem seus negócios.

Neste contexto, os profissionais de marketing adequaram as teorias fundamentais do comércio real para atenderem as necessidades deste novo mercado virtual, buscando consolidar um atendimento individualizado e contínuo. $\mathrm{O}$ foco no relacionamento com o cliente passou a ser a garantia da entrega do produto, fortalecendo a área de logística que no mercado virtual é a certeza do sucesso.

Diane do exposto, é recomendável que a empresa do ramo de essência La Bella Essenza siga as dicas deste material de estudo, proposto em formato de artigo científico, com o intuito de alavancar e ampliar seu leque de conhecimento no uso de suas estratégias de captação e fidelização de clientes. Cada autor citado, cada referência, cada pesquisa feita, fará com que a empresa possa tomar decisões melhores nas escolhas de suas estratégias, facilitando a compreensão sobre o assunto com metodologias fáceis de serem aplicadas no dia a dia.

Sugere-se, então, a importância de um bom atendimento desde a abordagem inicial. O profissional tem que saber ouvir seu cliente e entender o que ele precisa. Através do sucesso deste contato, pode-se afirmar que foi criada uma relação entre o cliente e a empresa, que o negócio foi fechado, podendo assim torná-lo fidelizado.

\section{REFERÊNCIAS}

CAMPANO, Jefeson. Como criar seu negocio online. 3. ed. São Paulo: JM Digital, 2010. 
CARDOSO, Cármen. Fidelização de clientes. Disponível em: http://www.notitia.truenet.com.br. Acesso em: 05 de jun. 2012.

FAGUNDES, Eduardo. O que é o e-commerce. 2009. Disponível em: https://efagundes.com/artigos/o-que-e-e-commerce/\#content. Acesso em: 02 jul. 2020.

GONÇALVES, Helmer José. Fidelização de Clientes. Monografia. 2007. Programa de Pósgraduação da Escola de Administração da UFRGS. Disponível em: https://lume.ufrgs.br/bitstream/handle/10183/14026/000649603.pdf. Acesso em: 11 jul. 2020.

KIYOSAKI, Robert T. Escola de Negócios. Rio de Janeiro: Elsevier, 2013.

KOTLER, Philip. Marketing 4.0. Rio de Janeiro: Sextante, 2017.

PAULILlO, Julio. AGENDOR BLOG. O custo total para o cliente. Disponível em: https://www.agendor.com.br/blog/. Acesso em: 03 jul. 2020.

\section{APÊNDICE A - Modelo de questionário semiaberto aplicado}

1. A empresa tem política de fidelização de clientes?

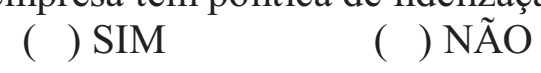

Se sim, quais são utilizadas:
a) E-mail marketing
b) Cartão para fidelização de cliente
c) Workflow
d) Outras:

2. A empresa utiliza as redes sociais como marketing e comunicação para atrair clientes?

$$
\text { ( ) SIM ( ) NÃO }
$$

Se sim, quais são utilizadas:
a) Instagram
b) Facebook
c) Youtube
d) Outras: LinkedIn

3. Quais as vantagens e desvantagens da rede social?

R: O número de captação de clientes é uma das vantagens, mas um grande percentual desta captação representa atendimentos que são descartados. Outra vantagem é a rápida 
pulverização de lançamento ou oferta. A desvantagem ocorre quando não há um cálculo preciso para suprir a demanda ou logística.

4. Qual é a sua abordagem para dar continuidade ao atendimento com o cliente da rede social?

R: Nossas campanhas possuem uma linguagem objetiva e direcionada ao públicoalvo. Indicamos a opção de conhecer o nosso site onde encontrará acesso ao mix de itens e informações relevantes ao processo de fabricação, ou ligar diretamente para a empresa e receber estas informações por e-mail, esclarecendo todas as dúvidas.

5. Qual é o papel das mídias sociais no seu processo de vendas?

R: O foco é a captação de clientes e pulverização da marca. A velocidade em chegar aos lugares mais distantes é representativo e lucrativo. Estar na rede social com campanhas agradáveis e objetivas também muda a imagem de nossa empresa, tornandoa mais próxima e amigável.

6. Quando você deve parar de trabalhar um cliente?

R: O conceito cliente para nós é: o individuo empreendedor ou a empresa produtora que usa uma marca concorrente ou irá utilizar nossos itens em novo projeto. $\mathrm{O}$ descarte ocorre na seleção quando a PF ou PJ não tem aplicação de nossos itens, ou se não se enquadra na política comercial de atendimento de venda em atacado. Já sendo um cliente, ele próprio se descarta quando se torna inadimplente ou opta por padrões abaixo de nossa qualidade.

7. A empresa oferece promoções aos clientes? Essas promoções levam a fidelização?
( ) SIM
( ) NÃO

R: As promoções visam desovar estoques ou venda rápida de lançamentos. A fidelização não ocorre com uma oferta e sim com os resultados obtidos após a aquisição do item. As promoções são praticamente uma forma de entrar na empresa alvo a fim de obter proximidade de atendimento.

8. Quais tipos de logística a empresa aplica?
a) Produção
b) Suprimentos
c) Reversa
d) Distribuição

9. Quais formas de pagamento a sua empresa utiliza?
a) Depósito
b) Boleto
c) Cartão de Crédito
d) Todas Acima 
10. Qual a frequência que a empresa posta novos conteúdos? Tem retorno considerável?

R: Diariamente temos conteúdos novos na rede social. Sim, são lucrativos e eficientes.

11. Qual o número de visitantes mensais? E desses quantos fidelizam o atendimento?

R: A média mensal de visitas (Site e Redes Sociais) é de $899.5 \%$ dos acessos têm retorno eficiente e convertido em venda.

12. Como está o relacionamento com os seguidores nas mídias sociais? Você responde as mensagens privadas e os comentários públicos de seus fãs na rede social usada?

R: Nenhuma pergunta ou elogio fica sem resposta. Por termos um produto de processo industrial e sendo nosso atendimento focado na Pessoa Jurídica ou empreendedores raramente há trocas de mensagens. 